\title{
Strategi Dakwah Islam Pengurus Jama'ah Pengajian Rutin Malam Sabtu Kliwon Di Dusun. Kresek, Desa. Pandak, Kec. Balong, Kab. Ponorogo
}

\author{
Mohammad Rivai \\ Institut agam,a islam sunan giri ponorogo \\ muhrivai@gmail.com
}

\begin{abstract}
Abstrak
Tujuan dari penelitian strategi dakwah islam jama'ah pengajian rutin setiap malam sabtu kliwon Dusun Kresek Desa Pandak untuk mengetahui bagaimana strategi dakwah para da'i khususnya dan para pengurus jama'ah yang dituntut menyesuaikan keadaan masyarakat yang semakin berkembang, rumusan masalah penelitian sebagai berikut : Apa strategi yang digunakan jama'ah pengajian rutin malam sabtu kliwon untuk menyebarkan agama Islam di Dusun Kresek Desa Pandak. Dalam penelitian ini penulis menggunakan pendekatan sosiologis dengan dengan melakukan observasi partisipan dan wawancara sebagai metode dalam pengumpulan data. Sedangkan metode kualitatif diskriptif digunakan untuk mengetahui karakteristik sumber data langsung, deskriptif bersifat triangulation yaitu teknik pemeriksaan data dengan memanfaatkan sesuatu yang lain sebagai perbandingan diluar data yang ditemukan, pengambialan subyek di Dusun Kresek Desa Pandak. Kesimpulan dari penelitian ini adalah strategi dakwah jama'ah pengajian rutin setiap malam sabtu kliwon Dusun Kresek Desa Pandak dalam mensyi arka Islam yang dituntut untuk menyesuaikan dengan faktor keberagaman masyarakat dan perkembangan Zaman yang semakin maju, baik dari segi politik, ekonomi, pendidikan, budaya dan sebagainya, mempunyai pengaruh yang sangat besar terhadap kelancaran proses Dakwah Islam. Mulai dari subyek dakwah, obyek dakwah, materi, metode, dan media dakwah harus menggunakan strategi yang benar-benar sesuai keadaan masyarat sekarang.
\end{abstract}

Kata Kunci : Dakwah Islam, Jama'ah Pengajian, Rutinan

\section{Abstract}

The purpose of the research on Islamic da'wah strategies for the congregation's regular recitation every Saturday night, Kliwon Kresek, Pandak Village, is to find out how the da'i strategy of the da'i in particular and the congregation's administrators are required to adapt to the growing conditions of society, the formulation of the research problem is as follows: What is the strategy used by the congregation for the regular Saturday night recitation of Kliwon to spread Islam in the Kresek Hamlet, Pandak Village. In this study, the authors used a sociological approach by conducting participant observation and interviews as a method of data collection. While descriptive qualitative methods are used to determine the characteristics of direct data sources, descriptive triangulation is a technique of examining data by utilizing something else as a comparison outside of the data found, taking subjects in Dusun Kresek, Pandak Village. The conclusion of this research is the strategy of preaching the congregation's regular recitation every Saturday night, Kliwon Dusun Kresek, Pandak Village in mensyi'arka Islam which is required to adapt to the diversity factor of society and the development of an increasingly advanced era, both in terms of politics, economy, education, culture. and so on, have a very large influence on the smooth process of Islamic Da'wah. Starting from the subject of da'wah, 
the object of da'wah, materials, methods, and media of da'wah must use a strategy that really fits the current state of society.

Keywords: Islamic Da'wah, Study Congregations, Routines

\section{A. Pendahuluan}

Ajakan atau dakwah sering dipahami secara sempit identik dengan pengajian umum yang dilakukan diatas podium. Seorang da'i hanya dianggap orang yang profesional dalam menyampaikan paengajian tersebut. Padahal sebenarnya pengertian dakwah itu sangat luas tidak hanya sebatas pengajian di atas podium. Pengertian dakwah adalah segala perbuatan dalam rangka amar ma'ruf nahi munkar (memerintahkan yang baik dan mencegah yang keji/munkar).(Rafiudin : 1997). Pada awalnya kata ini dipergunakan untuk kepentingan meliter saja, tetapi kemudian berkembang keberbagai bidang yang berbeda seperti strategi bisnis, ekonomi, pendidikan, pemasaran, menejemen, dakwah dan berbagai bidang yang lain.

Strategi ini dalam segala hal digunakan untuk mencapai tujuan yang telah ditetapkan. Tujuan tidak akan mudah dicapai tanpa srategi karena pada dasarnya segala tindakan atau perbuatan itu tidak lepas dari strategi. Adapun taktik sebenarnya merupakan cara yang digunakan dan merupakan bagian dari strategi.

Ajaran Islam berisi petunjuk - petunjuk agar manusia secara individual ataupun kelompok menjadi manusia yang baik, beradab, beriman dan berkualitas sehingga bisa bersaing dalam menghadapi perubahan jaman yang akhirnya mampu membangun peradaban yang maju, menuju suatu tatanan kehidupan yang manusiawi dalam arti kehidupan yang adil, maju dan bebas dari berbagai ancaman penindasan, dan berbagai kekhawatiran. Untuk mencapai itu diperlukan yang namanya dakwah (Rofiah : 2010).

Agama Islam adalah Agama Dakwah (Zamrani : 2012) artinya agama yang mendorong setiap umatnya untuk menyebar luaskan ajaran Islam seluruh masyarakat, dengan cara yang bijaksana, nasehat yang baik, serta berdebat dengan cara yang baik pula (Syam : 2003) dari yang bersifat pembinaan maupun yang bersifat pengembangan, yang bersifat pengembangan artinya usaha untuk mempertahankan, melestarikan, dan menyempurnakan umat manusia agar mereka tetap beriman kepada Allah SWT, sedangkan yang bersifat pengembangan artinya usaha mengajak umat manusia yang belum beriman kepada Allah SWT agar memeluk Islam supaya nantinya bisa hidup bahagia dan sejahtera didunia dan akhirat. 
Dengan demikian jelaslah bahwa Islam adalah agama yang didalamnya ada uaha untuk menyebarkan kebenaran dan mengajak kepada manuia untuk melakanakan apa yang menjadi perintah dan larangan ALLAH. Dakwah wajib diemban oleh setiap umat Islam baik itu laki-laki ataupun perempuan dengan penuh keadaran dan rasa tanggung jawab, bahkan dakwah kita menjadi tugas rutin dan kesinambungan dari masa ke masa sampai kelak di kemudian hari.

Dakwah Islam selalu mengambil peran penting dalam setiap kehidupan baik yang pribadi maupun yang bersentuhan langsung dengan realitas sosial sejak kelahiranya, persentuhan antara kenyataan dimasyarakat dengan dakwah Islam memunculkan dua kemungkinan, yang pertama dakwah Islam akan menghasilkan out put ( hasil/pengaruh) terhadap lingkungan masyarakat dalam arti memberikan pijakan hidup, arah dan pijakan mengadakan perbaikan serta perubahan yang lebih baik sehingga terbentuk tatanan masyarakat baru yang lebih baik. Yang kedua adalah dakwah Islam dipengaruhi oleh perubahan masyarakat baik secara corak maupun arahnya, ini berarti bahwa dakwah Islam ditentukan oleh sistem yang ditentukan oleh sistem yangberada dimasyarakat tersebut.(Hafi 2003).

Dakwah telah mengalami banya kemajuan, dengan kata lain dakwah menepati posisiyang tinggi dan mulia dalam kemajuan islam. Tidak dapat dibayangkan bilaaktifitas dakwah mengalami kelumpuhan yang disebabkan berbagai faktor. Lebih-lebih di era globalisasi sekarang ini yang berbagai informasi masuk begitu cepatdan instan tidak dapat dibendung lagi Dampak dari pernyataan ialam adalah agama dakwah, menuntut umatnya agar selalu menyampaikan dakwah karena kegiatan ini merupakan aktivitas yang tidak pernah usai selama kehidupan dunia masih berlangsungdan akan terus melekat dalam situasi dan kondisi apapun bentuk dan coraknya. (Zamrani 2013)

Strategi dakwah yang ada di masyarakat sangatlah beragam adanya, sangat bermacammacam strategi yang digunakan oleh subjek dakwah sesuai kemampuan seorang da'i dalam berdakwah dan organisasi dakwah yang ada dimasyarakat, dan juga dituntut untuk bisa menyesuaikan dengan perkembangan zaman sekarang ini, dalam kegiatan dakwah yang kita kenal dan umumnya yang sudah membumi di masyarakat yaitu pengajian umum, pengajian akbar, pengajian rutin dan sebagainya yang kelihatan monoton dan itu-itu saja sebenarnya tidak benar. Masyarakat saat ini mulai mampu mengimbangi perkembangan zaman globalisasi yang kita alami sekarang ini, kegiatan dakwah yang ada dalam pengajian tersebut mulai ada perubahan didalamnya, bahkan mereka membentuk organisasi yang menangani dakwah tersebut dam mulai 
terselip cara dakwah yang mengikuti tren sekarang. Para pengurus mulai membuat buku dakwah, jurnal dakwah, buleti, lewat pengajian radio, pengajian di televisi dan sholawat seperti yang trend saat ini di kalangan masyarakat ponorogo. Berangkat dari latar belakang diatas penulis timbul niat untuk meneliti strategi dakwah Islam yang diterapkan oleh Jamaah Pengajain Rutin Sabtu Kliwon yang berada di Dusun Kresek Desa Pandak Kecamatan Balong sehingga bisa diterima dimasyarakat.

\section{B. Metode Penelitian}

Pendekatan yang digunakan dalam penelitian ini adalah menggunakan pendekatan kualitatif yaitu penelitian yang hasilnya berupa data deskriptif melalui pengumpulan fakta-fakta dari kondisi alami sebagai sumber langsungdengan instrumen dari peneliti sendiri. Metode Kualitatif sebagai prosedur penelitian yang yang menghasilkan data deskriptif berupa kata-kata tertulis atau lisan dari orang-orang dan perilaku yang dapat diamati. (Surahmad : 1978)

Jenis penelitian yang digunakan peneliti adalah penelitian kualitatif (qualitative research) sebagai suatu penelitian yang diajukan untuk mendiskripsikan dan menganalisisfenomena, aktifitas sosial, sikap, kepercayaan ,presepsi, pemikiran secara individual ataupun kelompok. Beberapa deskripsi tersebut digunakan untuk menemukan prinsip-prinsipdan penjelasan yang menju kesimpulan.(Faisal 1982).

\section{Hasil Penelitian}

Jama'ah pengajian rutin setiap malam sabtu kliwon yang berada di Dusun Kresek Kecamatan Balong ini adalah salah satu organisasi atau lembaga dakwah yang konsisten dan terus berkembang hingga sekarang walaupun jama'ah tersebut bertempat di pedesaan yang notabene masyarakat dengan kelas ekonominya menengah kebawah yang mata pencaharianya adalah mayoritas profesinya sebagai petani dan sisanya sebagai pedagang, pegawai negeri, pegawai swasta dan ada juga beberapa orang berprofesi sebagai peternak baik itu peternak ayam, kambing dan sebagainya. Jama'ah yang berdiri pada tahun 2009 ini hingga sekarang masih konsisten dengan kegiatan yang diselenggarakan.

Desa pandak adalah desa yang terletak di bagian paling ujung barat daya dari kecamatan balong, perjalan dari kampus INSURI (Institut Agama Islam Sunan Giri) menggunakan sepedah motor memerlukan sekitar kurang lebih satu jam perjalanan. Walaupun desa Pandak ini terletak di kawasan pinggir dan jauh dari kota namun masykarakatnya tidak terlalu ketinggalan dari desa- 
desa yang lain yang lebih maju baik itu dari segi pembangunan sosial, kemasyarakatan, tingkat pendidikan dan lainya.

Untuk pendidikan agama sendiri masyarakat desa pandak terutama dusun krasek sudah mengalami peningkatan dari sebelumnya dan sudah banyak lembaga-lembaga dakwah yang lain didirikan untuk mensyiarkan agama islam. Dusun kresek adalah dusun yang paling strategis diantar lima dusun lain yang ada di desa Pandak karena letaknya yang berada di tengah-tengah desa dan terdapat jalur utama desa. Dusun Kresek ini sangatlah tepat dijadikan sebagai sentral dakwah yang berada di desa pandak terbukti dusun Kresek berdiri lembaga-lembaga dakwah yang bersifat menyeluruh dan menjangkau seluruh jama'ah yang ada di desa Pandak.

Untuk kondisi jama'ah sendiri terdiri dari 1 (satu) masjid dan 3 (tiga) mushola yang mana dari keempat jama'ah tersebut yang menjadi sentral adalah Masjid At-Taqwa yang mana digunakan sebagai tempat sholat jum'at seluruh jama'ah, walaupu sekretariat lembaga jama'ah pengajian rutin ini berada di gedung Al-Mawadah yang berada tepat disamping mushola AlMawadah beserta lembaga-lembaga dakwah yang lain.

\section{Visi Misi Organisasi}

Setiap suatu organisasi pasti memiliki visi dan misi masing-masing begitu juga jama'ah pengajian rutin setiap malam sabtu Kliwon di Desa pandak ini, visinya sebagai berikut:

a. Menjadi Kholifah fil Ardi

b. Menyampaikan walau satu ayat

c. Menjaga kerukunan bermasyarakat

Jama'ah ini memiliki visi untuk mewujudkan tujuan mereka dalam berdakwah jangka panjang dan juga dakwah jangka pendek, visi tersrbut dijadikan sebagai pondasi dasa dan utama untuk merealisasikan segala bentuk kegiatan dakwah dan program-prograng yang lain bisa tercapai dengan maksimal.

Sebagai lembaga yang memiliki eksistensi dalam kehidupan masyarakat dan untuk merealisasikan visi tersebut organisasi merumuskan misi yang mengarah ke tujuan program jangka pendek dan program jangka panjang yang mengarah jelas, dan berikut visi misi yang dirumuskan organisasi tersebut:

a. Meningkatkan semangat kerukunan sosial jama'ah yang luas

b. Meningkatkan kwalitas ibadah jama'ah 
c. Meningkatkan kesadaran masyarakat akan beragama

2. Tujuan jama'ah Pengajian

Adapun tujuan didirikanya jama'ah pengajian rutin setiap malam sabtu kliwon ini adalah meningkatkan dan mencetak manusia yang bertawa kepada Allah SWT, berakhlaqul karimah, memiliki kesadaran beragama yang tinggi, mempunyai kesadaran sosial yang tinggi sehingga terciptanya suatu masyarakat yang agamis dan rukun dalam kebersamaan, menjunjung tinggi nilai-nilai islam dan selalu berdakwah walaupun hanya satu ayat.

Adapun tujuan yang utama didirikanya jama'ah pengajian tersebut adalah meningkatkan kerukunan antara warga desa, karena mereka memandang ketika kerukunan itu sudah tercipta dalam suatu masyarakat maka akan mudah untuk mengerjakan sesuatu dan bisa meminimalisir hambatan-hambatan yanga ada, bahkan untuk melakukan dakwah islam itu sendiri.

3. Struktur Organisasi Jama'ah Pengajian

Adapun struktur organisasinya adalah:

\begin{tabular}{|c|c|c|}
\hline \multirow[t]{2}{*}{ Ketua } & \multicolumn{2}{|c|}{ : 1. Sugianto } \\
\hline & \multicolumn{2}{|c|}{ 2. Sunaryadi } \\
\hline \multirow[t]{2}{*}{ Sekretaris } & \multicolumn{2}{|c|}{ : 1. Bonasir } \\
\hline & \multicolumn{2}{|c|}{ 2. Sujianto } \\
\hline \multirow[t]{2}{*}{ Bendahara } & \multicolumn{2}{|c|}{ : 1. Wahono } \\
\hline & \multicolumn{2}{|c|}{ 2. Miswanto } \\
\hline \multirow[t]{7}{*}{ Seksi-seksi } & : A. PHBI & : 1. Jemadi \\
\hline & & 2. Jemari \\
\hline & \multicolumn{2}{|c|}{ B. Khotaman : 1. Khoirudin } \\
\hline & & 2. Supriyanto \\
\hline & \multirow[t]{3}{*}{ C. Humas } & : 1. Sarni \\
\hline & & 2. Sutikno \\
\hline & & 3. Jemiran \\
\hline
\end{tabular}

$\begin{array}{rr}\text { Koordinator } \quad \text { A. At-Taqwa } & : \text { 1.Sabar } \\ & 2 . \text { Boimin } \\ \text { B. Darul Iman } \quad: \text { 1. Sarni }\end{array}$




\section{Supriyanto}

C. Al-Hudust : 1 Bonasir

2. Suradi

D. Al-Mawadah $\quad:$ 1. Boiman

2. Misdi

Struktur Organisasi di atas adalah subjek dakwah dari jama'ah pengajian rutin setiap malam sabtu kliwon Dusun Kresek Desa Pandak, merekalah penggerak masyarakat Dusun Kresek yang mempunyai peran penting dalam terlaksananya kegiatan rutin tersebut, walaupun ada pula orang lain yang membantu peran mereka dalam menjalankan kegiatan pengajian rutin tersebut.

\section{Keadaan Jama'ah}

Jama'ah pengajian ini terdiri dari seluruh jama'ah masjid dan mushola yang berada di desa Pandak dan utamanya jama'ah dusun Kresek itu sendiri karena fokus awal objek dakwah adalah jama'ah lingkungan dusun Kresek.

Untuk jama'ah sendiri tidak membedakan antara golongan masyarakat, strata sosial yang dimiliki masyarakat, semua termasuk dalam anggota pengajian.

Untuk keadaan pendidikan jama'ah sendiri rata-rata sudah mengenyam pendidikan formal apalagi untuk yang generasu muda rata-rata sudah lulus SMA sederajat bahkan sudah ada yang sarjana dan itu mempermudah terlaksanaya kegiatan pengajian tersebut.

\section{Keadaan Pengurus}

Keadaan pengurus jama'ah yang notabene dari berbagai latar belakang pendidikan yang berbeda, ada yang lulusan SMA ada yang lulusan SD dan lain sebagainya, namun tidak menghalangi mereka dalam berinteraksi dan berkomunikasi, dalam merancang kegiataan dakwah, malah menjadi solusi tersendiri bagi para pengurus menghadapi jama'ah yang heterogen dan memunyai latar belakang pendidikan dan sosial yang berbeda-beda pula.

Namun walaupun mereka dari latar belakang pendidikan formal dan status sosial yang berbeda-beda akan tetapi mereka tidak luput dalam hal mengenyam pendidikan pesantren atau 
belajar ilmu agama islam yang mumpuni sehingga mereka juga tidak canggung daam urusan agama.

\section{Sarana Dan Prasarana}

Sarana adalah suatu alat utama yang menunjang segala kegiatan dakwah yang dilakukan baik dari perorangan maupun dakwang tang dilakukan oleh suatu lembaga. Tak terkecuali jama'ah pengajian rutin setiap malam sabtu kliwon dusun kresek desa Pandak ini, namun jama'ah belum mempunyai sendiri sarana dan prasarana yang mendukung suksesnya kegiatan dakwah jama'ah tersebut. Dalam setiap mengadakan pengajian rutin menggunakan sarana yang masih menyewa, Sekretariat pun masih belum punya dan masih satu dengan organisasi dakwah lainyang ada di desa Pandak seperti GP Anshor dan lainya yang masih menjadi satu.

Untuk pengajian rutin keliling atau yang diadakan disetiap masjid dan mushola masih mengandalkan warga yang ditempati untuk mempersiapkan sarananya, seperti son sistem, terop, dan lain sebagainya.

\section{Kesimpulan}

Berdasarkan analisa data maka dapat ditarik kesimpulan bahwa Strategi dakwah Islam Jama'ah Pengajian Rutin Setiap Malam Sabtu Kliwon Dusun Kresek Desa Pandak yaitu :

1. Dari Subjek dakwah para jama'ah memeilih Da'i yang sesuai dengan kondisi masyarakat dan bisa memahami keadaan Dusun Kresek Desa Pandak.

2. Dari Obyek Dakwah mereka memilah-milah obyek yang ada antara karang taruana, anak-anak dan masyarakat umum.

3. Dari Materi Dakwah dengan cara menyesuaikan dengan kemampuan masyarakat di Dusun Kresek Desa Pandak .

4. Dari Metode Dakwah mengunakan metode sesuai Al Qur'an dan sesuai masyarakat di Dusun Kresek Desa Pandak.

Dari Media Dakwah yang mengunakan media dakwah yang sesuai dengan kondisi masyarakat yang ada di Desa Pandak, mulai dari Seni Budaya, Madrasah Diniyah, Yasinan, Karang tarunna, dan sebagainya yang sementara sudah berjalan dengan rutin dan tertat.

\section{DAFTAR PUSTAKA}

Achmad Amrullah. 1983 Dakwah Islam dan Perubahan Sosial. Yogyakarta: Prima Duta Anshori Hafi.1993.Pemahaman dan Pengalaman Dakwah. Surabaya: Al-Ikhlas 
Ancok Jamaluddin.1994.Psikologi Islam. Yogyakarta: Pustaka Pelajar

Awaludin. 2008. Strategi Dakwah Nahdlatul Ulama Dalam Membentengi Warga Nahdiyin Dari Islam Radikal” (Studi Kasus Pengurus Cabang Nahdlatul Ulama Kota Semarang Periode 2001-2006). Skripsi Institut Agama Islam Negeri Walisongo Semarang

Asep Muhyidin et. all,. 2002.Metode pengembangan dakwah. Bandung: Pustaka Setia

Awaluddin Pimay.2006. Metodologi Dakwah Kajian Teoritis Dari Khazanah Al-Quran. Semarang: RaSAIL

Bambang Indrayana, "Problematika Dakwah Pesantren Al-IdrisBanyudono Ponorogo" Skripsi Institut Sunan Giri Ponorogo 2015.

Heri Setiawan, "Problematika Dakwah Islam Pesantren Rakyat Ar-Ridho Dukuh Sidowayah Kecamatan Jambon kabupaten Ponorogo”. Skripsi Institut Sunan Giri Ponorogo 2013.

Khusniati Rofiah. 2010 Dakwah Jamaah Tablig \& Eksistnsinya Dimata Masyarakat Ponorogo: STAIN Ponorogo Press

Lexy,J. Moelong. 1995.Metode Penelitian Kualitatif. Bandung: Remaja Rosdakarya.

Muhammad Zamroji.2012.Manhaj Dakwah Insan Pesantren,Dasar Dan Panduan Praktis Strategi Pengembangan Daskwah Islamiyah. Kediri: Kalam Santri Press.

M. Munir et.al.2009. Manajemen Dakwah.Jakarta: Kencana Prenada Media Group. M. Munir et.al.2009. Manajemen Dakwah.Jakarta: Kencana Prenada Media Group. Rafi'udin. et. oll.1997Prinsip dan Strategi Dakwah. Bandung: Pustaka Setia. Sanapiah faisal. 1982. Metodologi penelitian. Surabaya: Usaha Nasional. Sutrisno Hadi. 1990. Metodologi Research I. Jakarta: Anndi Offet.

Suharsimi Arikunto. 19998. Prosedur Penelitian: Suatu Pendekaran Praktek. Jakarta: Rineka Cipta.

Wahiddin Saputra. 2011 Pengantar Ilmu Dakwah. Jakarta: Raja Grafindo Persada.

Wahidin Saputra. 2011.Pengantar Ilmu Dakwah. Jakarta: Rajawali Press.

Winarno Surahmad. 1978.Dasar dan Teknik Research Pengantar Metodologi Ilmiyah. Bandung: Tarsito.

Yunus Hanis Syam. 2003.Managemen Dakwah dengan Tulisan Sebuah Peluang. Yogyakarta: Panji Pustaka 